\title{
Methamphetamine Causes Microglial Activation in the Brains of Human Abusers
}

\author{
Yoshimoto Sekine, ${ }^{1,2}$ Yasuomi Ouchi, ${ }^{4}$ Genichi Sugihara, ${ }^{5}$ Nori Takei,${ }^{5}$ Etsuji Yoshikawa, ${ }^{6}$ Kazuhiko Nakamura, ${ }^{2}$ \\ Yasuhide Iwata, ${ }^{2}$ Kenji J. Tsuchiya, ${ }^{5}$ Shiro Suda, ${ }^{2}$ Katsuaki Suzuki, ${ }^{2}$ Masayoshi Kawai, ${ }^{2}$ Kiyokazu Takebayashi, ${ }^{2}$ \\ Shigeyuki Yamamoto, ${ }^{5}$ Hideo Matsuzaki, ${ }^{7}$ Takatoshi Ueki, ${ }^{3}$ Norio Mori, ${ }^{2,5}$ Mark S. Gold, ${ }^{8}$ and Jean L. Cadet ${ }^{1}$ \\ ${ }^{1}$ Molecular Neuropsychiatry Branch, National Institute on Drug Abuse, Intramural Research Program, National Institutes of Health, Department of Health \\ and Human Services, Baltimore, Maryland 21224, Departments of ${ }^{2}$ Psychiatry and Neurology and ${ }^{3}$ Anatomy and Neuroscience, ${ }^{4}$ Molecular Imaging \\ Frontier Research Center, Hamamatsu University School of Medicine, ${ }^{5}$ Hamamatsu Center, Osaka-Hamamatsu Joint Research Center for Child Mental \\ Development, Higashi-ku, Hamamatsu, Shizuoka 431-3192, Japan, ${ }^{6}$ Central Research Laboratory, Hamamatsu Photonics, Hamakita-ku, Hamamatsu, \\ Shizuoka 434-8601, Japan, ${ }^{7}$ Osaka Center, Osaka-Hamamatsu Joint Research Center for Child Mental Development, Suita, Osaka 565-0871, Japan, and \\ ${ }^{8}$ Department of Psychiatry, Division of Addiction Medicine, University of Florida College of Medicine, Gainesville, Florida 32610-0183
}

\begin{abstract}
Methamphetamine is a popular addictive drug whose use is associated with multiple neuropsychiatric adverse events and toxic to the dopaminergic and serotonergic systems of the brain. Methamphetamine-induced neuropathology is associated with increased expression of microglial cells that are thought to participate in either pro-toxic or protective mechanisms in the brain. Although reactive microgliosis has been observed in animal models of methamphetamine neurotoxicity, no study has reported on the status of microglial activation in human methamphetamine abusers. The present study reports on 12 abstinent methamphetamine abusers and 12 age-, gender-, and education-matched control subjects who underwent positron emission tomography using a radiotracer for activated microglia, $\left[{ }^{11} \mathrm{C}\right](R)$-(1-[2-chlorophenyl]- $N$-methyl- $N$-[1-methylpropyl]-3-isoquinoline carboxamide) $\left(\left[{ }^{11} \mathrm{C}\right](R)-\mathrm{PK} 11195\right)$. Compartment analysis was used to estimate quantitative levels of binding potentials of $\left[{ }^{11} \mathrm{C}\right](R)$-PK11195 in brain regions with dopaminergic and/or serotonergic innervation. The mean levels of $\left[{ }^{11} \mathrm{C}\right](R)$-PK11195 binding were higher in methamphetamine abusers than those in control subjects in all brain regions $(>250 \%$ higher; $p<0.01$ for all). In addition, the binding levels in the midbrain, striatum, thalamus, and orbitofrontal and insular cortices $(p<0.05)$ correlated inversely with the duration of methamphetamine abstinence. These results suggest that chronic self-administration of methamphetamine can cause reactive microgliosis in the brains of human methamphetamine abusers, a level of activation that appears to subside over longer periods of abstinence.
\end{abstract}

Key words: methamphetamine; addiction; neurotoxicity; microglia; positron emission tomography; human

\section{Introduction}

Methamphetamine (METH) is a globally popular and highly addictive drug that can cause neuropsychiatric complications that include aggressive behaviors (Anglin et al., 2000; Freese et al., 2002). Long-term abuse of the drug is also associated with cognitive impairments (Volkow et al., 2001; Paulus et al., 2002; London et al., 2004; Thompson et al., 2004). The reported neuropsychological deficits might be related to the known neurodegenerative

\footnotetext{
Received March 18, 2008; revised May 1, 2008; accepted May 2, 2008.

This work was supported by a grant from the Japan-U.S. Cooperative Science Program of the Ministry of Education, Culture, Sports, Science and Technology, Japan and the U.S. National Science Foundation (Y.S., N.M., M.S.G., J.L.C.); a Grant-in-Aid for the Center of Excellence (N.T., N.M.) and a Grant-in-Aid for Scientific Research (Y.S.) from the Ministry of Education, Culture, Sports, Science and Technology, Japan; a Research Grant for Nervous and Mental Disorders from the Ministry of Health, Labour and Welfare, Japan (Y.S.); and the Department of Health and Human Services/National Institutes of Health/National Institute on Drug Abuse Intramural Research Program (J.L.C.). We thank Toshihiko Kanno and Masami Futatsubashi (Hamamatsu Medical Center) for their excellent technical support. Correspondence should be addressed to either Dr. Yasuomi Ouchi or Dr. Jean Lud Cadet, Molecular Neuropsychiatry Branch, National Institute on Drug Abuse, Intramural Research Program, National Institutes of Health, Department of Health and Human Services, 251 Bayview Boulevard, Baltimore, MD 21224, E-mail: ouchi@hama-med.ac.jp or jcadet@intra.nida.nih.gov.

D0I:10.1523/JNEUROSCI.1179-08.2008

Copyright $\odot 2008$ Society for Neuroscience $\quad 0270-6474 / 08 / 285756-06 \$ 15.00 / 0$
}

effects of the drug in animal models (Deng et al., 1999, 2002; Cadet et al., 2003, 2005; Jayanthi et al., 2005) and in the human dopaminergic (Volkow et al., 2001; Sekine et al., 2001, 2003) and serotonergic (McCann et al., 1998; Sekine et al., 2006) systems. These neuropathological changes were found to relate to the psychological and behavioral abnormalities, such as increased aggression and craving for the drug, observed in abstinent METH abusers (Sekine et al., 2001, 2006).

Microglial cells are involved in immune surveillance in the intact brain and are activated during neurodegenerative processes (Kreutzberg, 1996). The accumulated evidence suggests that activated microglial cells might also be triggered during the process of METH-induced toxicity in animals (Ladenheim et al., 2000; LaVoie et al., 2004; Thomas et al., 2004a,b; Thomas and Kuhn, 2005a). Nevertheless, it remained to be determined whether the chronic abuse of the drug was also associated with microglial activation in the brains of human METH addicts.

Recent advances in neuroimaging techniques have made it possible to visualize microglial activation by positron emission tomography (PET) using $\left[{ }^{11} \mathrm{C}\right](R)-(1$-[2-chlorophenyl]$N$-methyl- $N$-[1-methylpropyl]-3-isoquinoline carboxamide) 


\begin{tabular}{|c|c|c|c|c|}
\hline & \multicolumn{2}{|c|}{ Control subjects $(n=12)$} & \multicolumn{2}{|c|}{ METH abuser $(n=12)$} \\
\hline & Mean (SD) & Range & Mean (SD) & Range \\
\hline Age (years) & $31.8(3.4)$ & $29-35$ & $31.0(3.5)$ & $29-35$ \\
\hline Education (years) & $11.0(1.5)$ & $9-12$ & $10.7(1.4)$ & $9-12$ \\
\hline Duration of methamphetamine use (years) & & & $6.8(3.9)$ & $1.2-12.0$ \\
\hline Duration of methamphetamine abstinence (years) & & & $1.8(1.4)$ & $0.5-4.0$ \\
\hline Scale for methamphetamine craving ${ }^{b}$ & & & $4.9(3.4)$ & $1-10$ \\
\hline Aggression questionnaire score ${ }^{c}$ & $30.6(1.6)$ & $29-34$ & $63.8\left(7.8^{*}\right)$ & $54-80$ \\
\hline
\end{tabular}

${ }^{a}$ The number of females and males in each group was four and eight, respectively.

${ }^{b}$ The subjective Drug Effect Rating Scale for Cocaine (Volkow et al., 1997) was modified and used. The scores can range from 1 to 10, with higher scores representing more intense craving.

'Higher scores represent greater aggression (Buss and Perry, 1992).

*Significantly different from control subjects ( $p<0.001$ by Mann-Whitney $U$ test).

$\left(\left[{ }^{11} \mathrm{C}\right](R)-\mathrm{PK} 11195\right)$, a radiotracer for activated microglia (Banati, 2002; Cagnin et al., 2002). Using this approach, the presence of activated microglia has been reported in the brains of humans who suffer from brain disorders such as Alzheimer's disease and Parkinson's disease (Banati et al., 2000; Cagnin et al., 2001; Ouchi et al., 2005). Given the neurodegenerative effects of METH and the evidence of METH-induced reactive microgliosis in animals, we reasoned that METH-abusing individuals might show increased expression of microglial cells in their brains. Herein, we report that the brains of METH addicts are characterized by prominent microglial activation in regions of dopaminergic and serotoninergic innervation in METH abusers.

\section{Materials and Methods}

Participants. The ethics committees of the Hamamatsu University School of Medicine and Hamamatsu Medical Center approved this study. Written informed consents were obtained from all participants after they were provided with a detailed explanation of the study procedures. Twelve currently abstinent METH abusers who had previously abused only METH (i.e., mono-drug abusers) and 12 age-, gender-, and educationmatched control subjects participated in this study (Table 1). Potential participants were recruited from the community by means of poster advertisements and word of mouth. The participants in the METH group were required to attend a weekly meeting at the Drug Detoxification and Rehabilitation Program Center of Hattori Mental Hospital to maintain and ensure abstinence until the PET study was conducted.

All the METH abusers had taken the drug recreationally and had no history of using toxic doses of the drug. None of the abusers had any history of hospitalization or treatment at psychiatric hospitals. Detailed history of the use of other illicit drugs, including ( \pm )3,4-methylenedioxymethamphetamine (MDMA), cocaine, cannabis, heroin, and toluene, was also obtained, because these substances are known to cause psychiatric symptoms and to affect neurotransmission (McCann et al., 1998; Bolla et al., 2003, 2005; Takebayashi et al., 2004). All the METH abusers were naive to neuropsychiatric medications, e.g., antipsychotics and antidepressants, and all participants were free from antiinflammatory and/or antibiotic agents before at least 1 month before the time of PET examination. The controls were healthy and had never used $\mathrm{METH}$, and none of them met any relevant criteria for any psychiatric disorder according to the Diagnostic and Statistical Manual of Mental Disorders-IV (American Psychiatric Association, 1994). None of the participants fulfilled either the alcohol- or the nicotine-related Diagnostic and Statistical Manual of Mental Disorders-IV criteria. These evaluations were determined using the Structured Clinical Interview for the Diagnostic and Statistical Manual of Mental Disorders-IV (First et al., 1997). To increase the accuracy of the abusers' profiles, detailed information on the duration of METH use and the history of psychiatric symptoms was retrospectively obtained by interviewing with the abusers and their family members. The period of METH use was defined as the duration between the first and last use. When intervals of abstinence longer than 1 month occurred during the duration of METH use as defined, these intervals were subtracted from the total duration value. The METH ab- stinence period was arbitrarily defined as the duration between the day of the last use of METH and that of the PET examination (Sekine et al., 2001, 2006). All participants showed no abnormality in brain magnetic resonance imaging (MRI).

Drug screening. During the weekly meeting at the Drug Detoxification and Rehabilitation Program Center, the absence of recent METH and other drug use was regularly confirmed using a rapid immunoassay for the qualitative detection of the metabolites of the following eight classes of drugs: amphetamine, including METH and MDMA; barbiturates; benzodiazepines; cocaine; methadone; opiates; tetrahydrocannabinol; and tricyclic antidepressants (Triage8; Biosite Diagnostics). In addition, the participants were tested for urinary hippuric acid, a biomarker of toluene use, using HPLC according to the standard diagnostic methods (Takebayashi et al., 2004). These assessments were also performed on the same day as the PET examination. When necessary, we assessed hair samples using HPLC, which enabled us to verify long periods of METH abstinence (Al-Dirbashi et al., 2000).

Clinical evaluation. The severity of aggression in METH abusers was evaluated using the Aggression Questionnaire (Buss and Perry, 1992); the scores can range from 29 to 145 , with higher scores representing greater aggression. In addition, the subjective Drug Effect Rating Scale for Cocaine (Volkow et al., 1997) was modified and used for the assessment of cravings for METH. The scores on this assessment can range from 1 to 10, with higher scores representing more intense craving sensations. These evaluations were performed on the day of the PET examination by a trained research psychiatrist blind to the PET results.

MRI and PET procedures. As described previously (Ouchi et al., 2005), we performed three-dimensional MRI scans just before PET measurements using a $0.3 \mathrm{~T}$ MRI unit (MRP7000AD; Hitachi Medical) and a high-resolution brain PET scanner with a capability of yielding 47 PET images simultaneously (model SHR 12000; Hamamatsu Photonics), respectively. All MRI and PET scans were set parallel to the anteriorposterior intercommissural line (Ouchi et al., 2005). Before dynamic PET scanning, a 20 min transmission scan was performed for attenuation correction using a germanium Ge 68/gallium Ga 68 source with the participant's head fixed by means of a radiosurgery-purpose thermoplastic face mask. Then, after a bolus intravenous injection of a $350 \mathrm{MBq}$ dose of $\left[{ }^{11} \mathrm{C}\right](R)$-PK11195, 32 serial PET scans (time frames: $4 \times 30,20 \times 60$, and $8 \times 300 \mathrm{~s}$ ) were performed for $62 \mathrm{~min}$.

Image analysis and kinetic modeling. The brain regions, especially those of cortical area, are known to be sensitive to the partial volume effect of atrophy caused by substance use, including METH use (Wang et al., 1993; Thompson et al., 2004). In the present study, to minimize the contribution of the partial volume effect, we used the following procedure as described previously (Sekine et al., 2001, 2006; Ouchi et al., 2005). First, we adjusted the MRI voxel size to the PET voxel size three dimensionally using image-processing software (DrView; Asahi Kasei) on a Sun workstation (HyperSPARC ss-20; Sun Microsystems). Then, these reformatted MRIs with three-dimensional scales and coordinates identical to those of the PET images were used as anatomic landmarks for the region of interest (ROI) setting. Subsequently, by referring to areas on the MRIs as anatomical landmarks, ROIs were carefully drawn to avoid the involvement of either the sulci or ventricles. An investigator masked to the 
Table 2. Correlation between $\left[{ }^{11} \mathrm{C}\right](R)-$ PK11195 binding potentials and clinical variables

\begin{tabular}{|c|c|c|c|c|c|c|c|c|}
\hline \multirow[b]{2}{*}{ Brain region } & \multicolumn{2}{|c|}{$\left[{ }^{11} \mathrm{C}\right](R)-\mathrm{PK} 11195$ binding potential ${ }^{a}$} & \multicolumn{2}{|c|}{ Duration of METH use ${ }^{b}$} & \multicolumn{2}{|c|}{$\begin{array}{l}\text { Duration of METH } \\
\text { abstinence }^{b}\end{array}$} & \multicolumn{2}{|c|}{$\begin{array}{l}\text { Aggression question- } \\
\text { naire scores }{ }^{b}\end{array}$} \\
\hline & Control subjects & METH abusers & $\tau$ & $p$ & $\tau$ & $p$ & $\tau$ & $p$ \\
\hline Midbrain & $0.08(0.03)$ & $0.29(0.20)^{*}$ & 0.39 & 0.084 & -0.66 & $0.004^{*}$ & 0.44 & 0.046 \\
\hline Striatum & $0.05(0.02)$ & $0.19(0.13)^{*}$ & 0.31 & 0.166 & -0.61 & $0.008^{*}$ & 0.49 & 0.027 \\
\hline Thalamus & $0.04(0.03)$ & $0.16(0.10)^{*}$ & 0.50 & 0.027 & -0.74 & $0.001^{*}$ & 0.49 & 0.027 \\
\hline Orbitofrontal cortex & $<0.01$ & $0.08(0.07)^{*}$ & 0.42 & 0.070 & -0.55 & 0.020 & 0.46 & 0.044 \\
\hline Insular cortex & $<0.01$ & $0.08(0.06)^{*}$ & 0.40 & 0.082 & -0.53 & 0.024 & 0.44 & 0.052 \\
\hline
\end{tabular}

${ }^{a}$ Data shown are mean (SD); the level of statistical significance was set at $p=0.01$ (Mann-Whitney $U$ test).

${ }^{b}$ Data shown are computed by using Kendall's $\tau(n=12$ for methamphetamine abusers); the level of statistical significance was set at $p=0.01$.

${ }^{*} p<0.01$.

participant's condition placed five ROIs bilaterally over the midbrain, striatum, thalamus, orbitofrontal cortex, and insular cortex on the MRIs according to previously described procedures. These ROIs were then transferred onto the corresponding dynamic $\left[{ }^{11} \mathrm{C}\right](R)$-PK11195 images. The obtained time-activity curves were used for the further analysis.

To assess the brain activated microglia density, we analyzed the $\left[{ }^{11} \mathrm{C}\right](R)$-PK11195 timeactivity curves on the basis of a simplified reference tissue model (Lammertsma et al., 1996; Banati et al., 2000), because the regional brain $\left[{ }^{11} \mathrm{C}\right](R)$-PK11195 binding potential (BP; a ratio of binding and dissociation rate constants, $k_{3} / k_{4}$ ) estimated by this model is reported to correlate with the magnitude of microglial activity (Banati et al., 2000; Ouchi et al., 2005). This procedure has been described previously (Ouchi et al., 2005). Briefly, a normalized input curve was first created by averaging the ROIs placed over the cerebral cortical regions, including the frontal, parietal, and occipital cortices in the control group. Then, the normalized mean tissue activity curve was used as the reference input function, because a desirable reference region free from specific binding is not present in patients with neurodegenerative disorders, including METH abusers. The normalized input curve derived from control group was used as the time-activity curve for the reference region of both the control subjects and METH abusers.

Statistical analysis. To compare demographic and clinical variables between control subjects and METH abusers, the Mann-Whitney $U$ test was used. To test the effect of METH use on $\left[{ }^{11} \mathrm{C}\right](R)-\mathrm{PK} 11195 \mathrm{BPs}$ in the five brain regions, we also used the Mann-Whitney $U$ test. Correlations between the $\left[{ }^{11} \mathrm{C}\right](R)$-PK11195 $\mathrm{BP}$ and clinical variables in METH abusers, including the duration of METH use and abstinence, were evaluated by using Kendall's $\tau$. To diminish the risk of type I error related to multiple testing, we set the level of statistical significance at $p=0.01$ (SPSS version 11.0J; SPSS Japan).

\section{Results}

Comparison of $\left[{ }^{11} \mathrm{C}\right](R)$-PK11195 binding between METH abusers and control subjects

METH abusers had significantly higher $\left[{ }^{11} \mathrm{C}\right](R)$-PK11195 BPs than control subjects in the five ROIs studied. These include the midbrain $(264 \% ; U=27.0 ; p=0.008)$, the striatum $(313 \% ; U=$ $23.0 ; p=0.004)$, thalamus $(297 \% ; U=21.0 ; p=0.002)$, orbitofrontal cortex $(1530 \% ; U=25.5 ; p=0.006)$, and insular cortex $(1520 \% ; U=25.5 ; p=0.006)$ (Table 2, Figs. $1,2 A)$. It is imporhealthy control (green).

\section{Methamphetamine abuser}
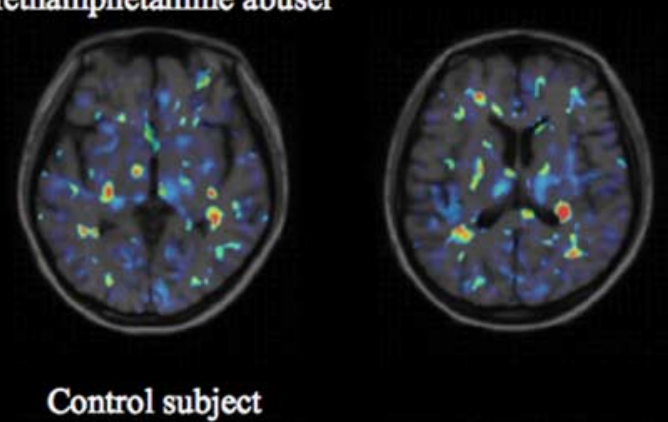

1. Magnetic resonance imaging-positron emission tomography fusion parametric images of $\left[{ }^{11} \mathrm{C}\right](R)-\mathrm{PK} 11195$ observed in widespread areas of the brain of the methamphetamine abuser. The color bar indicates a level of binding potential. Scattergrams show the time-activity curves of $\left[{ }^{11} \mathrm{C}\right](R)$-PK11195 for each region in the methamphetamine abuser (red) and

tant to note that the METH abusers who participated in the present study had taken the drug for $>6$ years and had been abstinent for almost 2 years, facts that indicate that the reported observations are not secondary to the acute effects of the drug.

\section{Correlation between $\left[{ }^{11} \mathrm{C}\right](R)-\mathrm{PK} 11195$ binding and clinical variables}

There were no significant correlations between the length of METH use and $\left[{ }^{11} \mathrm{C}\right](R)$-PK11195 BPs in any of the brain regions (Table 2). The duration of METH abstinence showed a significant negative correlation with the $\left[{ }^{11} \mathrm{C}\right](R)-\mathrm{PK} 11195 \mathrm{BPs}$ in three brain areas, namely the midbrain $(\tau=-0.657$; $p=$ $0.004)$, striatum $(\tau=-0.614 ; p=0.008)$, and thalamus $(\tau=$ $-0.743 ; p=0.001$ ) (Fig. $2 B$, Table 2). There were no significant 

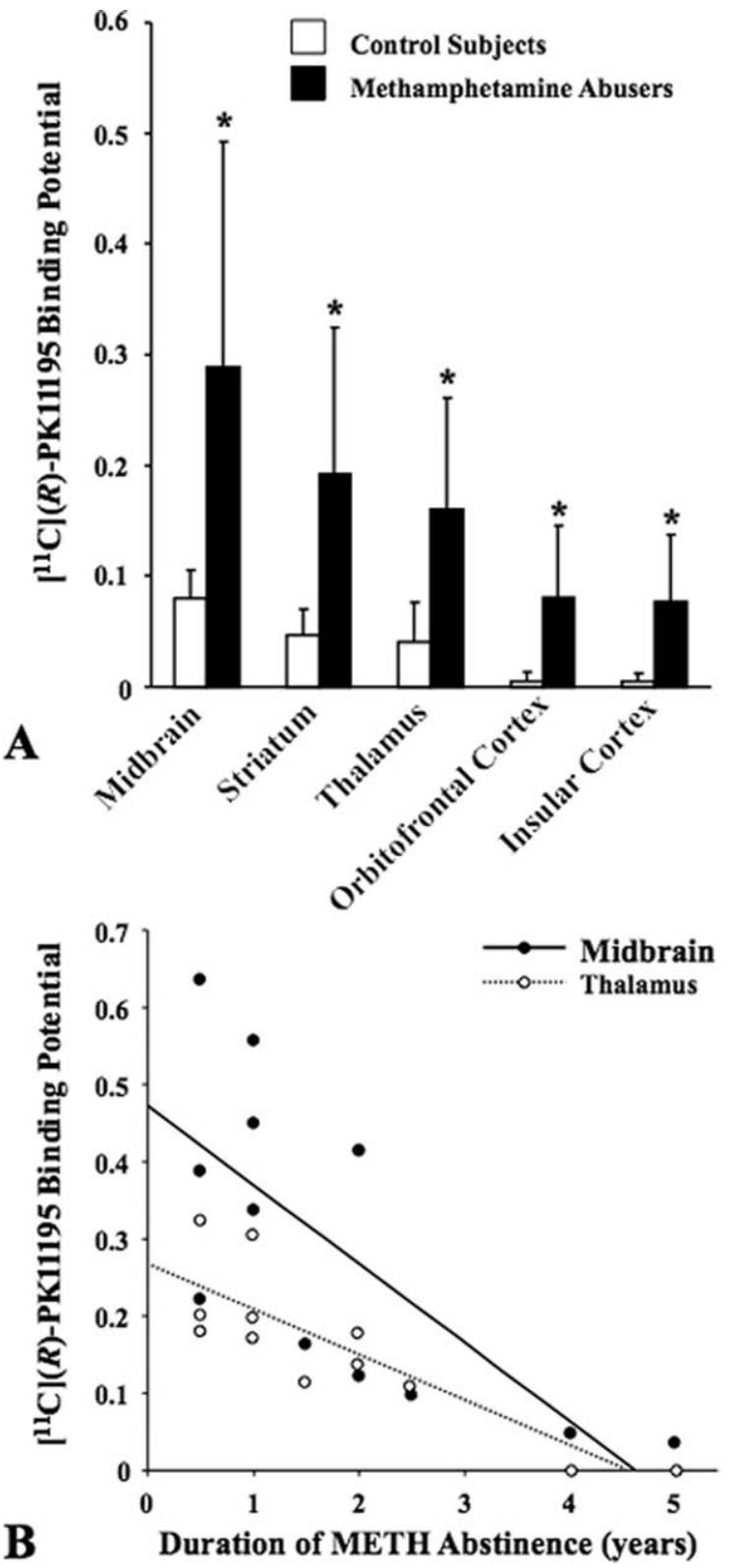

Figure 2. $\quad \boldsymbol{A}$, Mean levels of $\left[{ }^{11} \mathrm{C}\right](R)-\mathrm{PK} 11195 \mathrm{BP}$ in control subjects and METH abusers. The $\left[{ }^{11} \mathrm{C}\right](R)$-PK11195 BP levels were significantly higher in all brain regions of METH abusers $\left({ }^{*} p<\right.$ 0.01 for all by Mann-Whitney $U$ test). Error bars represent SD. $\boldsymbol{B}$, Correlations between $\left[{ }^{11} \mathrm{C}\right](R)$-PK11195 BP and the duration of METH abstinence in representative brain regions in METH abusers (midbrain, Kendall's $\tau=-0.657 ; p=0.004$; thalamus, $\tau=-0.743 ; p=$ 0.001).

correlations between $\left[{ }^{11} \mathrm{C}\right](R)-\mathrm{PK} 11195 \mathrm{BPs}$ and the magnitude of aggression in any of the brain regions examined. The subjective craving scores were not significantly correlated with changes in $\left[{ }^{11} \mathrm{C}\right](R)-\mathrm{PK} 11195 \mathrm{BPs}$ in any brain regions (data not shown). Despite reports on age-dependent increases in $\left[{ }^{11} \mathrm{C}\right](R)$ PK11195 BP (Cagnin et al., 2001; Ouchi et al., 2005), we found no such relation in our younger subjects, possibly because of the short age range of all subjects examined.

\section{Discussion}

The results of the present study show that $\left[{ }^{11} \mathrm{C}\right](R)-\mathrm{PK} 11195$ $\mathrm{BPs}$, which are representative measures of activated microglial density (Banati et al., 2000; Cagnin et al., 2001; Ouchi et al., 2005), are significantly increased in the midbrain, striatum, thal- amus, orbitofrontal cortex, and insular cortex of METH abusers. METH abusers who participated in this study denied any history of use of other illicit drugs, including MDMA, which has been reported to cause microglial reaction in both rats and mice (Orio et al., 2004; Thomas et al., 2004a,b; Zhang et al., 2006). These individuals had no previous history of hospitalization for any other psychiatric illnesses, such as affective disorders and schizophrenia, disorders reported to be associated with increased microglial density in the brain (Wierzba-Bobrowicz et al., 2005; Rajkowska and Miguel-Hidalgo, 2007). Thus, the reactive microgliosis observed presently appears to reflect the effect of METH alone on the human brain. This conclusion is consistent with the preclinical data on the use of METH in rodents (Ladenheim et al., 2000; Escubedo et al., 2005). This idea is also supported by the fact that injection of the drug in mice that mimic recreational dose regimen ( 4 times $\times 2 \mathrm{mg} / \mathrm{kg}$ injections per day given for a total of $3 \mathrm{~d}$ ) also caused significant increases in activated microglia in the mouse brain (Thomas and Kuhn, 2005a).

Multiple lines of evidence have suggested that activated microglia might be involved in causing neurodegeneration through proinflammatory processes, including the production of tumor necrosis factor- $\alpha$, interleukin- $1 \beta$, and interleukin- 6 or through oxidative mechanisms via the generation of superoxide radicals (Boje and Arora, 1992; Gruol and Nelson, 1997; Ehrlich et al., 1998; McGuire et al., 2001). Thus, microglial activation could trigger the onset of a cascade of events that result in neurodegeneration processes. In fact, activation of microglia appears to precede METH-induced damage to striatal dopaminergic terminals in rodents (LaVoie et al., 2004; Thomas et al., 2004a,b; Thomas and Kuhn, 2005a). The report that METH-induced neurotoxicity is attenuated in interleukin-6-null mice provides further support for a potential role of activated microglia in the toxic effects of the drug (Ladenheim et al., 2000). Furthermore, the nonsteroidal anti-inflammatory ketoprofen, the second-generation tetracycline minocycline, and the glutamate receptor antagonists MK801 and dextromethorphan all appear to attenuate METHinduced neurotoxicity via antimicroglial actions (Asanuma et al., 2003; Thomas and Kuhn, 2005b; Hashimoto et al., 2007). When taken together with these observations, the present findings suggest that METH-induced activated microglia in humans might also play an important role in mediating the toxic effects of the drug on monoaminergic terminals observed in METH-using populations of patients (McCann et al., 1998; Sekine et al., 2001, 2003, 2006; Volkow et al., 2001). Although the earlier studies of METH-induced microglial activation had focused mostly in brain regions of high DA content (LaVoie et al., 2004; Thomas and Kuhn, 2005a) that are known to be severely affected by METH (Cadet et al., 2003), the accumulated evidence now suggests that chronic use of METH might cause more global pathological changes in the brain (Sekine et al., 2001, 2003, 2006; London et al., 2004). Thus, when taken together with the present observations of a more global microglial activation in the brains of the METH abusers, it is not farfetched to suggest that the abuse of this drug might be associated with hitherto unknown neuropathological changes in the human brain. It is also important to point out that our observations that reactive microgliosis can last for, at least, 2 years of abstinence suggest that METH-induced neurodegeneration might be an ongoing process. These statements have obvious treatment implications.

Although the present study was not designed to directly assess the progress of changes in microglial activation over time, the density value of the activated microglia was found to negatively correlate with the duration of METH abstinence in METH abus- 
ers (all were $p<0.05$ ) (Table 2, Fig. $2 B$ ). Furthermore, after an approximately 2 year abstinence of METH abuse, the number of activated microglia had normalized (Fig. 2 B). These observations suggest that protracted abstinence from METH use can lead to normalization of microglial function in the brain. This assumption is supported in the animal literature, which documents a normalization of the number of microglial cells after 1 week postMETH injections (Thomas et al., 2004a,b). These arguments are consistent with the report by Volkow et al. (2001) that the loss of dopamine transporters in METH abusers recovers with protracted abstinence. Nevertheless, other groups of investigators have reported that $\mathrm{METH}$-induced loss of dopamine transporter and/or serotonin transporter is more persistent over the long term (McCann et al., 1998; Sekine et al., 2001, 2006). One possibility is that the extent and duration of microglial activation might alter the degree of neuronal recovery.

To our knowledge, the present study is the first to demonstrate significant increases in the number of microglial cells in the METH-addicted living human brain. Our observations suggest that there is normalization of these processes during protracted abstinence from use of the drug. The present findings, combined with the results of preclinical studies, suggest the importance of early therapeutic intervention with either anti-inflammatory or other neuroprotective agents in humans who use METH.

\section{References}

Al-Dirbashi OY, Kuroda N, Wada M, Takahashi M, Nakashima K (2000) Quantification of methamphetamine, amphetamine and enantiomers by semi-micro column HPLC with fluorescence detection; applications on abusers' single hair analyses. Biomed Chromatogr 14:293-300.

American Psychiatric Association (1994) Diagnostic and statistical manual of mental disorders, Ed 4. Washington, D.C.: American Psychiatric.

Anglin MD, Burke C, Perrochet B, Stamper E, Dawud-Noursi S (2000) History of the methamphetamine problem. J Psychoactive Drugs 32:137-141.

Asanuma M, Tsuji T, Miyazaki I, Miyoshi K, Ogawa N (2003) Methamphetamine-induced neurotoxicity in mouse brain is attenuated by ketoprofen, a non-steroidal anti-inflammatory drug. Neurosci Lett 352:13-16.

Banati RB, Newcombe J, Gunn RN, Cagnin A, Turkheimer F, Heppner F, Price G, Wegner F, Giovannoni G, Miller DH, Perkin GD, Smith T, Hewson AK, Bydder G, Kreutzberg GW, Jones T, Cuzner ML, Myers R (2000) The peripheral benzodiazepine binding site in the brain in multiple sclerosis: quantitative in vivo imaging of microglia as a measure of disease activity. Brain 123:2321-2337.

Banati RB (2002) Visualising microglial activation in vivo. Glia 40:206-217.

Boje KM, Arora PK (1992) Microglial-produced nitric oxide and reactive nitrogen oxides mediate neuronal cell death. Brain Res 587:250-256.

Bolla KI, Eldreth DA, London ED, Kiehl KA, Mouratidis M, Contoreggi C, Matochik JA, Kurian V, Cadet JL, Kimes AS, Funderburk FR, Ernst M (2003) Orbitofrontal cortex dysfunction in abstinent cocaine abusers performing a decision-making task. NeuroImage 19:1085-1094.

Bolla KI, Eldreth DA, Matochik JA, Cadet JL (2005) Neural substrates of faulty decision-making in abstinent marijuana users. NeuroImage 26:480-492.

Buss AH, Perry M (1992) The aggression questionnaire. J Pers Soc Psychol 63:452-459.

Cadet JL, Jayanthi S, Deng X (2003) Speed kills: cellular and molecular bases of methamphetamine-induced nerve terminal degeneration and neuronal apoptosis. FASEB J 17:1775-1788.

Cadet JL, Jayanthi S, Deng X (2005) Methamphetamine-induced neuronal apoptosis involves the activation of multiple death pathways. Neurotox Res 8:199-206.

Cagnin A, Brooks DJ, Kennedy AM, Gunn RN, Myers R, Turkheimer FE, Jones T, Banati RB (2001) In-vivo measurement of activated microglia in dementia. Lancet 358:461-467.

Cagnin A, Gerhard A, Banati RB (2002) In vivo imaging of neuroinflammation. Eur Neuropsychopharmacol 12:581-586.

Deng X, Ladenheim B, Tsao LI, Cadet JL (1999) Null mutation of c-fos causes exacerbation of methamphetamine-induced neurotoxicity. J Neurosci 19:10107-10115.

Deng X, Jayanthi S, Ladenheim B, Krasnova IN, Cadet JL (2002) Mice with partial deficiency of c-Jun show attenuation of methamphetamineinduced neuronal apoptosis. Mol Pharmacol 62:993-1000.

Ehrlich LC, Hu S, Sheng WS, Sutton RL, Rockswold GL, Peterson PK, Chao CC (1998) Cytokine regulation of human microglial cell IL-8 production. J Immunol 160:1944-1948.

Escubedo E, Chipana C, Pérez-Sánchez M, Camarasa J, Pubill D (2005) Methyllycaconitine prevents methamphetamine-induced effects in mouse striatum: involvement of $\alpha 7$ nicotinic receptors. J Pharmacol Exp Ther 315:658-667.

First MB, Spitzer RL, Gibbon M, Williams JBW (1997) Structured clinical interview for the diagnostic and statistical manual of mental disorders, fourth edition, patient version. Washington, D.C.: American Psychiatric.

Freese TE, Miotto K, Reback CJ (2002) The effects and consequences of selected club drugs. J Subst Abuse Treat 23:151-156.

Gruol DL, Nelson TE (1997) Physiological and pathological roles of interleukin-6 in the central nervous system. Mol Neurobiol 15:307-339.

Hashimoto K, Tsukada H, Nishiyama S, Fukumoto D, Kakiuchi T, Iyo M (2007) Protective effects of minocycline on the reduction of dopamine transporters in the striatum after administration of methamphetamine: a positron emission tomography study in conscious monkeys. Biol Psychiatry 61:577-581.

Jayanthi S, Deng X, Ladenheim B, McCoy MT, Cluster A, Cai NS, Cadet JL (2005) Calcineurin/NFAT-induced up-regulation of the Fas ligand/Fas death pathway is involved in methamphetamine-induced neuronal apoptosis. Proc Natl Acad Sci USA 102:868-873.

Kreutzberg GW (1996) Microglia: a sensor for pathological events in the CNS. Trends Neurosci 19:312-318.

Ladenheim B, Krasnova IN, Deng X, Oyler JM, Polettini A, Moran TH, Huestis MA, Cadet JL (2000) Methamphetamine-induced neurotoxicity is attenuated in transgenic mice with a null mutation for interleukin-6. Mol Pharmacol 58:1247-1256.

Lammertsma AA, Bench CJ, Hume SP, Osman S, Gunn K, Brooks DJ, Frackowiak RS (1996) Comparison of methods for analysis of clinical $\left[{ }^{11} \mathrm{C}\right]$ raclopride studies. J Cereb Blood Flow Metab 16:42-52.

LaVoie MJ, Card JP, Hastings TG (2004) Microglial activation precedes dopamine terminal pathology in methamphetamine-induced neurotoxicity. Exp Neurol 187:47-57.

London ED, Simon SL, Berman SM, Mandelkern MA, Lichtman AM, Bramen J, Shinn AK, Miotto K, Learn J, Dong Y, Matochik JA, Kurian V, Newton T, Woods R, Rawson R, Ling W (2004) Mood disturbances and regional cerebral metabolic abnormalities in recently abstinent methamphetamine abusers. Arch Gen Psychiatry 61:73-84.

McCann UD, Szabo Z, Scheffel U, Dannals RF, Ricaurte GA (1998) Positron emission tomographic evidence of toxic effect of MDMA ("ecstasy") on brain serotonin neurons in human beings. Lancet 352:1433-1437.

McGuire SO, Ling ZD, Lipton JW, Sortwell CE, Collier TJ, Carvey PM (2001) Tumor necrosis factor alpha is toxic to embryonic mesencephalic dopamine neurons. Exp Neurol 169:219-230.

Orio L, O'Shea E, Sanchez V, Pradillo JM, Escobedo I, Camarero J, Moro MA, Green AR, Colado MI (2004) 3,4-Methylenedioxymethamphetamine increases interleukin-1beta levels and activates microglia in rat brain: studies on the relationship with acute hyperthermia and 5-HT depletion. J Neurochem 89:1445-1453.

Ouchi Y, Yoshikawa E, Sekine Y, Futatsubashi M, Kanno T, Ogusu T, Torizuka T (2005) Microglial activation and dopamine terminal loss in early Parkinson's disease. Ann Neurol 57:168-175.

Paulus MP, Hozack NE, Zauscher BE, Frank L, Brown GG, Braff DL, Schuckit MA (2002) Behavioral and functional neuroimaging evidence for prefrontal dysfunction in methamphetamine-dependent subjects. Neuropsychopharmacology 26:53-63.

Rajkowska G, Miguel-Hidalgo JJ (2007) Gliogenesis and glial pathology in depression. CNS Neurol Disord Drug Targets 6:219-233.

Sekine Y, Iyo M, Ouchi Y, Matsunaga T, Tsukada H, Okada H, Yoshikawa E, Futatsubashi M, Takei N, Mori N (2001) Methamphetamine-related psychiatric symptoms and reduced brain dopamine transporters studied with PET. Am J Psychiatry 158:1206-1214.

Sekine Y, Minabe Y, Ouchi Y, Takei N, Iyo M, Nakamura K, Suzuki K, Tsukada H, Okada H, Yoshikawa E, Futatsubashi M, Mori N (2003) Association of dopamine transporter loss in the orbitofrontal and dorso- 
lateral prefrontal cortices with methamphetamine-related psychiatric symptoms. Am J Psychiatry 160:1699-1701.

Sekine Y, Ouchi Y, Takei N, Yoshikawa E, Nakamura K, Futatsubashi M, Okada H, Minabe Y, Suzuki K, Iwata Y, Tsuchiya KJ, Tsukada H, Iyo M, Mori N (2006) Brain serotonin transporter density and aggression in abstinent methamphetamine abusers. Arch Gen Psychiatry 63:90-100.

Takebayashi K, Sekine Y, Takei N, Minabe Y, Isoda H, Takeda H, Nishimura K, Nakamura K, Suzuki K, Iwata Y, Sakahara H, Mori N (2004) Metabolite alterations in basal ganglia associated with psychiatric symptoms of abstinent toluene users: a proton MRS study. Neuropsychopharmacology 29:1019-1026.

Thomas DM, Kuhn DM (2005a) Attenuated microglial activation mediates tolerance to the neurotoxic effects of methamphetamine. J Neurochem 92:790-797.

Thomas DM, Kuhn DM (2005b) MK-801 and dextromethorphan block microglial activation and protect against methamphetamine-induced neurotoxicity. Brain Res 1050:190-198.

Thomas DM, Dowgiert J, Geddes TJ, Francescutti-Verbeem D, Liu X, Kuhn DM (2004a) Microglial activation is a pharmacologically specific marker for the neurotoxic amphetamines. Neurosci Lett 367:349-354.

Thomas DM, Walker PD, Benjamins JA, Geddes TJ, Kuhn DM (2004b) Methamphetamine neurotoxicity in dopamine nerve endings of the striatum is associated with microglial activation. J Pharmacol Exp Ther 311:1-7.

Thompson PM, Hayashi KM, Simon SL, Geaga JA, Hong MS, Sui Y, Lee JY,
Toga AW, Ling W, London ED (2004) Structural abnormalities in the brains of human subjects who use methamphetamine. J Neurosci 24:6028-6036.

Volkow ND, Wang GJ, Fischman MW, Foltin RW, Fowler JS, Abumrad NN, Vitkun S, Logan J, Gatley SJ, Pappas N, Hitzemann R, Shea CE (1997) Relationship between subjective effects of cocaine and dopamine transporter occupancy. Nature 386:827-830.

Volkow ND, Chang L, Wang GJ, Fowler JS, Leonido-Yee M, Franceschi D, Sedler MJ, Gatley SJ, Hitzemann R, Ding YS, Logan J, Wong C, Miller EN (2001) Association of dopamine transporter reduction with psychomotor impairment in methamphetamine abusers. Am J Psychiatry 158:377-382.

Wang GJ, Volkow ND, Roque CT, Cestaro VL, Hitzemann RJ, Cantos EL, Levy AV, Dhawan AP (1993) Functional importance of ventricular enlargement and cortical atrophy in healthy subjects and alcoholics as assessed with PET, MR imaging, and neuropsychologic testing. Radiology 186:59-65.

Wierzba-Bobrowicz T, Lewandowska E, Lechowicz W, Stepien T, Pasennik E (2005) Quantitative analysis of activated microglia, ramified and damage of processes in the frontal and temporal lobes of chronic schizophrenics. Folia Neuropathol 43:81-89.

Zhang L, Shirayama Y, Shimizu E, Iyo M, Hashimoto K (2006) Protective effects of minocycline on 3,4-methylenedioxymethamphetamineinduced neurotoxicity in serotonergic and dopaminergic neurons of mouse brain. Eur J Pharmacol 544:1-9. 